\title{
Convergence of a proximal point algorithm for maximal monotone operators in Hilbert spaces
}

Zhiqiang Wei ${ }^{1}$ and Guohong Shi ${ }^{2^{*}}$

\author{
* Correspondence: hbshigh@yeah. \\ net \\ ${ }^{2}$ College of Science, Hebei \\ University of Engineering, Handan \\ 056038, China \\ Full list of author information is \\ available at the end of the article
}

\begin{abstract}
In this article, we consider the proximal point algorithm for the problem of approximating zeros of maximal monotone mappings. Strong convergence theorems for zero points of maximal monotone mappings are established in the framework of Hilbert spaces.
\end{abstract}

2000 AMS Subject Classification: 47H05; 47H09; 47J25.

Keywords: fixed point, nonexpansive mapping, maximal monotone mapping, zero

\section{Introduction}

The theory of maximal monotone operators has emerged as an effective and powerful tool for studying many real world problems arising in various branches of social, physical, engineering, pure and applied sciences in unified and general framework. Recently, much attention has been payed to develop efficient and implementable numerical methods including the projection method and its variant forms, auxiliary problem principle, proximal-point algorithm and descent framework for solving variational inequalities and related optimization problems (see [1-32] and the references therein). The proximal point algorithm, can be traced back to Martinet [33] in the context of convex minimization and Rockafellar [34] in the general setting of maximal monotone operators, has been extended and generalized in different directions by using novel and innovative techniques and ideas.

In this article, we investigate the problem of approximating a zero of the maximal monotone mapping based on a proximal point algorithm in the framework of Hilbert spaces. Strong convergence of the iterative algorithm is obtained.

\section{Preliminaries}

Throughout this article, we assume that $H$ is a real Hilbert space, whose inner product and norm are denoted by $\langle.$,$\rangle and I I$. II, respectively. Let $T$ be a set-valued mapping.

(a) The set $D(T)$ defined by

$$
D(T)=\{u \in H: T(u) \neq \emptyset\}
$$

is called the effective domain of $T$. (c) 2012 Wei and Shi; licensee Springer. This is an Open Access article distributed under the terms of the Creative Commons Attribution License (http://creativecommons.org/licenses/by/2.0), which permits unrestricted use, distribution, and reproduction in any medium, provided the original work is properly cited. 
(b) The set $R(T)$ defined by

$$
R(T)=\bigcup_{u \in H} T(u)
$$

is called the range of $T$.

(c) The set $G(T)$ defined by

$$
G(T)=\{(u, v) \in H \times H: u \in D(T), v \in R(T)\}
$$

is said to be the graph of $T$.

Recall the following definitions.

(c) $T$ is said to be monotone if

$$
\langle u-v, x-y\rangle \geq 0, \quad \forall(u, x),(v, y) \in G(T) .
$$

(d) $T$ is said to be maximal monotone if it is not properly contained in any other monotone operator.

For a maximal monotone $T: D(T) \rightarrow 2^{H}$, we can defined the resolvent of $T$ by

$$
J_{t}=(I+t T)^{-1}, \quad t>0 .
$$

It is well known that $J_{t}: H \rightarrow D(T)$ is nonexpansive, and $F\left(J_{t}\right)=T^{-1}(0)$, where $F\left(J_{t}\right)$ denotes the set of fixed points of $J_{t}$. The Yosida approximation $T_{t}$ is defined by

$$
T_{t}=\frac{1}{t}\left(I-J_{t}\right), \quad t>0 .
$$

It is well known that $T_{t} x \in T J_{t} x, \forall x \in H$ and $\left\|T_{t} x\right\| \leq|T x|$, where

$$
|T x|=\inf \{\|y\|: y \in T x\},
$$

for all $x \in D(T)$.

Let $C$ be a nonempty, closed and convex subset of $H$. Next, we always assume that $T$ : $C \rightarrow 2^{H}$ is a maximal monotone mapping with $T^{-1}(0) \neq \emptyset$, where $T^{-1}(0)$ denotes the set of zeros of $T$.

The class of monotone mappings is one of the most important classes of mappings among nonlinear mappings. Within the past several decades, many authors have been devoting to the studies on the existence and convergence of zero points for maximal monotone mappings. A classical method to solve the following set-valued equation

$$
0 \in T x,
$$

is the proximal point algorithm. To be more precise, start with any point $x_{0} \in H$, and update $x_{n+1}$ iteratively conforming to the following recursion

$$
x_{n} \in x_{n+1}+\beta_{n} T x_{n+1}, \quad n \geq 0,
$$

where $\left\{\beta_{n}\right\} \subset[\beta, \infty),(\beta>0)$ is a sequence of real numbers. However, as pointed in [15], the ideal form of the method is often impractical since, in many cases, to solve the problem (2.3) exactly is either impossible or the same difficult as the original problem (2.2). Therefore, one of the most interesting and important problems in the theory of maximal monotone operators is to find an efficient iterative algorithm to compute approximately zeroes of $T$. 
In 1976, Rockafellar [35] gave an inexact variant of the method

$$
x_{0} \in H, \quad x_{n}+e_{n+1} \in x_{n+1}+\lambda_{n} T x_{n+1}, \quad n \geq 0,
$$

where $\left\{e_{n}\right\}$ is regarded as an error sequence. This is an inexact proximal point algorithm. It was shown that, if

$$
\sum_{n=0}^{\infty}\left\|e_{n}\right\|<\infty
$$

then the sequence $\left\{x_{n}\right\}$ defined by (1.4) converges weakly to a zero of $T$ provided that $T^{-1}(0) \neq \emptyset$. In [16], Güller obtained an example to show that Rockafellar's proximal point algorithm (1.4) does not converge strongly, in general.

Recently, many authors studied the problems of modifying Rockafellar's proximal point algorithm so that strong convergence is guaranteed. Cho et al. [13] proved the following result.

Theorem CKZ. Let $H$ be a real Hilbert space, $\Omega$ a nonempty closed convex subset of $H$, and $T: \Omega \rightarrow 2^{H}$ a maximal monotone operator with $T^{-1}(0) \neq \emptyset$. Let $P_{\Omega}$ be the metric projection of $H$ onto $\Omega$. Suppose that, for any given $x_{n} \in H, \beta_{n}>0$ and $e_{n} \in H$, there exists $\bar{x}_{n} \in \Omega$ conforming to the SVME (2.4), where $\left\{\beta_{n}\right\} \subset(0,+\infty)$ with $\beta_{n} \rightarrow \infty$ as $n \rightarrow \infty$ and

$$
\sum_{n=1}^{\infty}\left\|e_{n}\right\|^{2}<\infty .
$$

Let $\left\{\alpha_{n}\right\}$ be a real sequence in $[0,1]$ such that

(i) $\alpha_{n} \rightarrow 0$ as $n \rightarrow \infty$,

(ii) $\sum_{n=0}^{\infty} \alpha_{n}=\infty$.

for any fixed $u \in \Omega$, define the sequence $\left\{x_{n}\right\}$ iteratively as follows:

$$
x_{n+1}=\alpha_{n} u+\left(1-\alpha_{n}\right) P_{\Omega}\left(\bar{x}_{n}-e_{n}\right), \quad n \geq 0 .
$$

Then $\left\{x_{n}\right\}$ converges strongly to a fixed point $z$ of $T$, where $z=\lim _{t \rightarrow \infty} J_{t} u$.

In this article, motivated by Theorem CKZ, we continue to consider the problem of approximating a zero of the maximal monotone mapping $T$. Strong convergence theorems are established under mild restrictions imposed on the error sequence $\left\{e_{n}\right\}$ comparing with the restriction $(B)$. The results which include Cho et al. [13] as a special case also improve the corresponding results announced by many others.

In order to prove our main result, we need the following lemmas.

Lemma 2.1. (Bruck [[35], Lemma 1]). Let $H$ be a Hilbert space and $C$ a nonempty, closed and convex subset $H$. For all $u \in C, \lim _{t \rightarrow \infty} J_{t} u$ exists and it is the point of $T^{-1}$ (0) nearest $u$.

Lemma 2.2 (Eckstein [[15], Lemma 2]). For any given $x_{n} \in C, \lambda_{n}>0$, and $e_{n} \in H$, there exists $\bar{x}_{n} \in C$ conforming to the following set-valued mapping equation (in short, SVME):

$$
x_{n}+e_{n} \in \bar{x}_{n}+\lambda_{n} T \bar{x}_{n} .
$$


Furthermore, for any $p \in T^{-1}(0)$, we have

$$
\left\langle x_{n}-\bar{x}_{n}, x_{n}-\bar{x}_{n}+e_{n}\right\rangle \leq\left\langle x_{n}-p, x_{n}-\bar{x}_{n}+e_{n}\right\rangle
$$

and

$$
\left\|\bar{x}_{n}-e_{n}-p\right\|^{2} \leq\left\|x_{n}-p\right\|^{2}-\left\|x_{n}-\bar{x}_{n}\right\|^{2}+\left\|e_{n}\right\|^{2} .
$$

Lemma 2.3 (Liu [36]). Assume that $\left\{\alpha_{n}\right\}$ is a sequence of nonnegative real numbers such that

$$
\alpha_{n+1} \leq\left(1-\gamma_{n}\right) \alpha_{n}+\delta_{n}
$$

where $\left\{\gamma_{n}\right\}$ is a sequence in $(0,1)$ and $\left\{\delta_{n}\right\}$ is a sequence such that

(i) $\sum_{n=1}^{\infty} \gamma_{n}=\infty$;

(ii) $\lim \sup _{n \rightarrow \infty} \delta_{n} / \gamma_{n} \leq 0$ or $\sum_{n=1}^{\infty}\left|\delta_{n}\right|<\infty$.

Then $\lim _{n \rightarrow \infty} \alpha_{n}=0$.

\section{Main results}

Theorem 3.1. Let $H$ be a real Hilbert space, $C$ a nonempty, closed and convex subset of $H$ and $T: C \rightarrow 2^{H}$ a maximal monotone operator with $T^{-1}(0) \neq \emptyset$. Let $P_{C}$ be a metric projection from $H$ onto $C$. For any $x_{n} \in H$ and $\lambda_{n}>0$, find $\bar{x}_{n} \in C$ and $e_{n} \in H$ conforming to the SVME (2.5), where $\left\{\lambda_{n}\right\} \subset(0, \infty)$ with $\lambda_{n} \rightarrow \infty$ as $n \rightarrow \infty$ and

$$
\left\|e_{n}\right\| \leq \eta_{n}\left\|x_{n}-\bar{x}_{n}\right\|
$$

with $\sup _{n \geq 0} \eta_{n}=\eta<1$. Let $\left\{\alpha_{n}\right\}$ and $\left\{\beta_{n}\right\}$ be real sequences in $[0,1]$ satisfying $\alpha_{n}+$ $\beta_{n}<1$ and the following control conditions:

$$
\lim _{n \rightarrow \infty} \alpha_{n}=\lim _{n \rightarrow \infty} \beta_{n}=0 \text { and } \sum_{n=0}^{\infty} \alpha_{n}=\infty .
$$

Let $\left\{x_{n}\right\}$ be a sequence generated by the following manner:

$$
x_{0} \in H, \quad x_{n+1}=\alpha_{n} u+\beta_{n} x_{n}+\left(1-\alpha_{n}-\beta_{n}\right) P_{C}\left(\bar{x}_{n}-e_{n}\right) . \quad n \geq 0,
$$

where $u \in C$ is a fixed element. Then the sequence $\left\{x_{n}\right\}$ generated by (3.1) strongly converges to a zero point $z$ of $T$, where $z=\lim _{t \rightarrow \infty} J_{t} u$, if and only if $e_{n} \rightarrow 0$ as $n \rightarrow \infty$.

Proof. First, show that the necessity. Assume that $x_{n} \rightarrow z$ as $n \rightarrow \infty$, where $z \in T^{-1}$ (0). It follows from (2.5) that

$$
\begin{aligned}
\left\|\bar{x}_{n}-z\right\| & \leq\left\|x_{n}-z\right\|+\left\|e_{n}\right\| \\
& \leq\left\|x_{n}-z\right\|+\eta_{n}\left\|x_{n}-\bar{x}_{n}\right\| \\
& \leq\left(1+\eta_{n}\right)\left\|x_{n}-z\right\|+\eta_{n}\left\|\bar{x}_{n}-z\right\| .
\end{aligned}
$$

This implies that

$$
\left\|\bar{x}_{n}-z\right\| \leq \frac{1+\eta_{n}}{1-\eta_{n}}\left\|x_{n}-z\right\| .
$$

It follows that $\bar{x}_{n} \rightarrow z$ as $n \rightarrow \infty$. Note that

$$
\left\|e_{n}\right\| \leq \eta_{n}\left\|x_{n}-\bar{x}_{n}\right\| \leq \eta_{n}\left(\left\|x_{n}-z\right\|+\left\|z-\bar{x}_{n}\right\|\right) .
$$


This shows that $e_{n} \rightarrow 0$ as $n \rightarrow \infty$.

Next, we show the sufficiency. The proof is divided into three steps.

Step 1. Show that $\left\{x_{n}\right\}$ is bounded.

From the assumption $(C)$, we see that

$$
\left\|e_{n}\right\| \leq\left\|x_{n}-\bar{x}_{n}\right\| .
$$

For any $p \in T^{-1}(0)$, it follows from Lemma 2.2 that

$$
\begin{aligned}
\left\|P_{C}\left(\bar{x}_{n}-e_{n}\right)-p\right\|^{2} & \leq\left\|\bar{x}_{n}-e_{n}-p\right\|^{2} \\
& \leq\left\|x_{n}-p\right\|^{2}-\left\|x_{n}-\bar{x}_{n}\right\|^{2}+\left\|e_{n}\right\|^{2} \\
& \leq\left\|x_{n}-p\right\|^{2} .
\end{aligned}
$$

That is,

$$
\left\|P_{C}\left(\bar{x}_{n}-e_{n}\right)-p\right\| \leq\left\|x_{n}-p\right\| .
$$

It follows from (3.2) that

$$
\begin{aligned}
\left\|x_{n+1}-p\right\| & =\left\|\alpha_{n}(u-p)+\left(1-\alpha_{n}\right)\left[P_{C}\left(\bar{x}_{n}-e_{n}\right)-p\right]\right\| \\
& \leq \alpha_{n}\|u-p\|+\left(1-\alpha_{n}\right)\left\|P_{C}\left(\bar{x}_{n}-e_{n}\right)-p\right\| \\
& \leq \alpha_{n}\|u-p\|+\left(1-\alpha_{n}\right)\left\|x_{n}-p\right\| .
\end{aligned}
$$

Putting

$$
M=\max \left\{\left\|x_{0}-p\right\|,\|u-p\|\right\},
$$

we show that $\left\|x_{n}\right\| \leq M$ for all $n \geq 0$. It is easy to see that the result holds for $n=0$. Assume that the result holds for some $n \geq 0$. That is, $\left\|x_{n}-p\right\| \leq M$. Next, we prove that $\left\|x_{n+1}-p\right\| \leq M$. Indeed, we see from (3.3) that

$$
\left\|x_{n+1}-p\right\| \leq M \text {. }
$$

This shows that the sequence $\left\{x_{n}\right\}$ is bounded.

Step 2. Show that $\lim \sup _{n \rightarrow \infty}\left\langle u-z, x_{n+1}-z\right\rangle \leq 0$, where $z=\lim _{t \rightarrow \infty} J_{t} u$.

From Lemma 2.1, we see that $\lim _{t \rightarrow \infty} J_{t} u$ exists, which is the point of $T^{-1}(0)$ nearest to $u$. Since $T$ is maximal monotone, $T_{t} u \in T J_{t} u$ and $T_{\lambda_{n}} x_{n} \in T J_{\lambda_{n}} x_{n}$, we see

$$
\begin{aligned}
& \left\langle u-J_{t} u, J_{\lambda_{n}} x_{n}-J_{t} u\right\rangle \\
& =-t\left\langle T_{t} u, J_{t} u-J_{\lambda_{n}} x_{n}\right\rangle \\
& =-t\left\langle T_{t} u-T_{\lambda_{n}} x_{n}, J_{t} u-J_{\lambda_{n}} x_{n}\right\rangle-t\left\langle T_{\lambda_{n}} x_{n}, J_{t} u-J_{\lambda_{n}} x_{n}\right\rangle \\
& =-\frac{t}{\lambda_{n}}\left\langle x_{n}-J_{\lambda_{n}} x_{n}, J_{t} u-J_{\lambda_{n}} x_{n}\right\rangle .
\end{aligned}
$$

Since $\lambda_{n} \rightarrow \infty$ as $n \rightarrow \infty$, for any $t>0$, we have

$$
\limsup _{n \rightarrow \infty}\left\langle u-J_{t} u, J_{\lambda_{n}} x_{n}-J_{t} u\right\rangle \leq 0 .
$$

On the other hand, by the nonexpansivity of $J_{\lambda n}$, we obtain

$$
\left\|J_{\lambda_{n}}\left(x_{n}+e_{n}\right)-J_{\lambda_{n}} x_{n}\right\| \leq\left\|\left(x_{n}+e_{n}\right)-x_{n}\right\|=\left\|e_{n}\right\| .
$$


From the assumption $e_{n} \rightarrow 0$ as $n \rightarrow \infty$ and (3.4), we arrive at

$$
\limsup _{n \rightarrow \infty}\left\langle u-J_{t} u, J_{\lambda_{n}}\left(x_{n}+e_{n}\right)-J_{t} u\right\rangle \leq 0 .
$$

From (2.5), we see that

$$
\left\|P_{C}\left(\bar{x}_{n}-e_{n}\right)-J_{\lambda_{n}}\left(x_{n}+e_{n}\right)\right\| \leq\left\|\left(\bar{x}_{n}-e_{n}\right)-J_{\lambda_{n}}\left(x_{n}+e_{n}\right)\right\| \leq\left\|e_{n}\right\| .
$$

That is,

$$
\lim _{n \rightarrow \infty}\left\|P_{C}\left(\bar{x}_{n}-e_{n}\right)-J_{\lambda_{n}}\left(x_{n}+e_{n}\right)\right\|=0 .
$$

Combining (3.5) with (3.6), we arrive at

$$
\limsup _{n \rightarrow \infty}\left\langle u-J_{t} u, P_{C}\left(\bar{x}_{n}-e_{n}\right)-J_{t} u\right\rangle \leq 0 .
$$

On the other hand, we see from the algorithm (3.1) that

$$
x_{n+1}-P_{C}\left(\bar{x}_{n}-e_{n}\right)=\alpha_{n}\left[u-P_{C}\left(\bar{x}_{n}-e_{n}\right)\right]+\beta_{n}\left[x_{n}-P_{C}\left(\bar{x}_{n}-e_{n}\right)\right] .
$$

It follows from the condition $\lim _{n \rightarrow \infty} \alpha_{n}=\lim _{n \rightarrow \infty} \beta_{n}=0$ that

$$
x_{n+1}-P_{C}\left(\bar{x}_{n}-e_{n}\right) \rightarrow 0 \text { as } n \rightarrow \infty,
$$

which combines with (3.7) yields that

$$
\limsup _{n \rightarrow \infty}\left\langle u-J_{t} u, x_{n+1}-J_{t} u\right\rangle \leq 0, \quad \forall t \geq 0 .
$$

From $z=\lim _{t \rightarrow \infty} J_{t} u$ and (3.8), we arrive at

$$
\limsup _{n \rightarrow \infty}\left\langle u-z, x_{n+1}-z\right\rangle \leq 0 .
$$

Step 3. Show that $x_{n} \rightarrow z$ as $n \rightarrow \infty$.

It follows from (3.2) that

$$
\begin{aligned}
\left\|x_{n+1}-z\right\|^{2}= & \left\langle\alpha_{n} u+\beta_{n} x_{n}+\left(1-\alpha_{n}-\beta_{n}\right) P_{C}\left(\bar{x}_{n}-e_{n}\right)-z, x_{n+1}-z\right\rangle \\
\leq & \alpha_{n}\left\langle u-z, x_{n+1}-z\right\rangle+\beta_{n}\left\langle x_{n}-z, x_{n+1}-z\right\rangle \\
& +\left(1-\alpha_{n}-\beta_{n}\right)\left\langle P_{C}\left(\bar{x}_{n}-e_{n}\right)-z, x_{n+1}-z\right\rangle \\
\leq & \alpha_{n}\left\langle u-z, x_{n+1}-z\right\rangle+\beta_{n}\left\|x_{n}-z\right\|\left\|x_{n+1}-z\right\| \\
& +\left(1-\alpha_{n}-\beta_{n}\right)\left\|P_{C}\left(\bar{x}_{n}-e_{n}\right)-z\right\|\left\|x_{n+1}-z\right\| \\
\leq & \alpha_{n}\left\langle u-z, x_{n+1}-z\right\rangle+\beta_{n}\left\|x_{n}-z\right\|\left\|x_{n+1}-z\right\| \\
& +\left(1-\alpha_{n}-\beta_{n}\right)\left\|x_{n}-z\right\|\left\|x_{n+1}-z\right\| \\
= & \alpha_{n}\left\langle u-z, x_{n+1}-z\right\rangle+\left(1-\alpha_{n}\right)\left\|x_{n}-z\right\|\left\|x_{n+1}-z\right\| \\
\leq & \alpha_{n}\left\langle u-z, x_{n+1}-z\right\rangle+\frac{1-\alpha_{n}}{2}\left(\left\|x_{n}-z\right\|^{2}+\left\|x_{n+1}-z\right\|^{2}\right) .
\end{aligned}
$$

This implies that

$$
\left\|x_{n+1}-z\right\|^{2} \leq\left(1-\alpha_{n}\right)\left\|x_{n}-z\right\|^{2}+\alpha_{n}\left\langle u-z, x_{n+1}-z\right\rangle .
$$

Applying Lemma 2.3 to (3.10), we obtain that $x_{n} \rightarrow z$ as $n \rightarrow \infty$. This completes the proof.

As a corollary of Theorem 3.1, we have the following. 
Corollary 3.2. Let $H$ be a real Hilbert space, $C$ a nonempty, closed and convex subset of $H$ and $T: C \rightarrow 2^{H}$ a maximal monotone operator with $T^{-1}(0) \neq \emptyset$. Let $P_{C}$ be a metric projection from $H$ onto $C$. For any $x_{n} \in H$ and $\lambda_{n}>0$, find $\bar{x}_{n} \in C$ and $e_{n} \in H$ conforming to the $\operatorname{SVME}(2.5)$, where $\left\{\lambda_{n}\right\} \subset(0, \infty)$ with $\lambda_{n} \rightarrow \infty$ as $n \rightarrow \infty$ and

$$
\left\|e_{n}\right\| \leq \eta_{n}\left\|x_{n}-\bar{x}_{n}\right\|
$$

with $\sup _{n \geq 0} \eta_{n}=\eta<1$. Let $\left\{\alpha_{n}\right\}$ be a real sequence in $(0,1)$ satisfying the following control conditions:

$$
\lim _{n \rightarrow \infty} \alpha_{n}=0 \text { and } \sum_{n=0}^{\infty} \alpha_{n}=\infty
$$

Let $\left\{x_{n}\right\}$ be a sequence generated by the following manner:

$$
x_{0} \in H, \quad x_{n+1}=\alpha_{n} u+\left(1-\alpha_{n}\right) P_{C}\left(\bar{x}_{n}-e_{n}\right) . \quad n \geq 0,
$$

where $u \in C$ is a fixed element. Then the sequence $\left\{x_{n}\right\}$ strongly converges to a zero point $z$ of $T$, where $z=\lim _{t \rightarrow \infty}, J_{t} u$, if and only if $e_{n} \rightarrow 0$ as $n \rightarrow \infty$.

Remark 3.3. Corollary 3.2 improves Theorem CKZ by relaxing the restriction imposed on the sequence $\left\{e_{n}\right\}$. In [34], Rockafellar obtained a weak convergence by assuming that $\sum_{n=0}^{\infty}\left\|e_{n}\right\|<\infty$, see [34] for more details.

Next, as applications of Theorem 3.1, we consider the problem of finding a minimizer of a convex function.

Let $H$ be a Hilbert space, and $f: H \rightarrow(-\infty,+\infty]$ be a proper convex lower semi-continuous function. Then the subdifferential $\partial f$ of $f$ is defined as follows:

$$
\partial f(x)=\{y \in H: f(z) \geq f(x)+\langle z-x, y\rangle, \quad z \in H\}, \quad \forall x \in H .
$$

Theorem 3.4. Let $H$ be a real Hilbert space and $f: H \rightarrow(-\infty,+\infty]$ a proper convex lower semi-continuous function. Let $\left\{\lambda_{n}\right\}$ be a sequence in $(0,+\infty)$ with $\lambda_{n} \rightarrow \infty$ as $n \rightarrow$ $\infty$ and $\left\{e_{n}\right\}$ a sequence in $H$ with $e_{n} \rightarrow \infty$ as $n \rightarrow \infty$. Assume that

$$
\left\|e_{n}\right\| \leq \eta_{n}\left\|x_{n}-\bar{x}_{n}\right\|
$$

with $\sup _{n \geq 0} \eta_{n}=\eta<1$. Let $\bar{x}_{n}$ be the solution of SVME (2.5) with T replacing by $\partial f$. That is,

$$
x_{n}+e_{n} \in \bar{x}_{n}+\lambda_{n} \partial f\left(\bar{x}_{n}\right), \quad \forall n \geq 0 .
$$

Let $\left\{\alpha_{n}\right\}$ and $\left\{\beta_{n}\right\}$ be real sequences in $[0,1]$ satisfying $\alpha_{n}+\beta_{n}<1$ and the following control conditions:

$$
\lim _{n \rightarrow \infty} \alpha_{n}=\lim _{n \rightarrow \infty} \beta_{n}=0 \text { and } \sum_{n=0}^{\infty} \alpha_{n}=\infty .
$$

Let $\left\{x_{n}\right\}$ be a sequence generated by the following manner:

$$
\left\{\begin{array}{l}
x_{0} \in H, \\
\bar{x}_{n}=\operatorname{argmin}_{x \in H}\left\{f(x)+\frac{1}{2 \lambda_{n}}\left\|x-x_{n}-e_{n}\right\|^{2}\right\}, \\
x_{n+1}=\alpha_{n} u+\beta_{n} x_{n}+\left(1-\alpha_{n}-\beta_{n}\right)\left(\bar{x}_{n}-e_{n}\right) . \quad n \geq 0,
\end{array}\right.
$$


where $u \in H$ is a fixed element. If $\partial f(0) \neq \emptyset$, the sequence $\left\{x_{n}\right\}$ converges strongly to a minimizer of $f$ nearest to $u$.

Proof. Since $f: H \rightarrow(-\infty,+\infty]$ is a proper convex lower semi-continuous function, we have that the subdifferential $\partial f$ of $f$ is maximal monotone by Theorem 1 of [34]. Notice that

$$
\bar{x}_{n}=\arg \min _{x \in H}\left\{f(x)+\frac{1}{2 \beta_{n}}\left\|x-x_{n}-e_{n}\right\|^{2}\right\}
$$

is equivalent to the following

$$
0 \in \partial f\left(\bar{x}_{n}\right)+\frac{1}{\lambda_{n}}\left(\bar{x}_{n}-x_{n}-e_{n}\right) .
$$

It follows that

$$
x_{n}+e_{n} \in \bar{x}_{n}+\lambda_{n} \partial f\left(\bar{x}_{n}\right), \quad \forall n \geq 0 .
$$

By Theorem 3.1, we can obtain the desired conclusion immediately.

As a corollary of Theorem 3.4, we have the following.

Corollary 3.5. Let $H$ be a real Hilbert space and $f: H \rightarrow(-\infty,+\infty]$ a proper convex lower semi-continuous function. Let $\left\{\lambda_{n}\right\}$ be a sequence in $(0,+\infty)$ with $\lambda_{n} \rightarrow \infty$ as $n \rightarrow$ $\infty$ and $\left\{e_{n}\right\}$ a sequence in $H$ with $e_{n} \rightarrow \infty$ as $n \rightarrow \infty$. Assume that

$$
\left\|e_{n}\right\| \leq \eta_{n}\left\|x_{n}-\bar{x}_{n}\right\|
$$

with $\sup _{n \geq 0} \eta_{n}=\eta<1$. Let $\bar{x}_{n}$ be the solution of SVME (2.5) with T replacing by $\partial f$. That is,

$$
x_{n}+e_{n} \in \bar{x}_{n}+\lambda_{n} \partial f\left(\bar{x}_{n}\right), \quad \forall n \geq 0 .
$$

Let $\left\{\alpha_{n}\right\}$ be a real sequence in $[0,1]$ ssatisfying the following control conditions:

$$
\lim _{n \rightarrow \infty} \alpha_{n}=0 \text { and } \sum_{n=0}^{\infty} \alpha_{n}=\infty \text {. }
$$

Let $\left\{x_{n}\right\}$ be a sequence generated by the following manner:

$$
\left\{\begin{array}{l}
x_{0} \in H \\
\bar{x}_{n}=\arg \min _{x \in H}\left\{f(x)+\frac{1}{2 \lambda_{n}}\left\|x-x_{n}-e_{n}\right\|^{2}\right\} \\
x_{n+1}=\alpha_{n} u+\left(1-\alpha_{n}\right)\left(\bar{x}_{n}-e_{n}\right) . \quad n \geq 0
\end{array}\right.
$$

where $u \in H$ is a fixed element. If $\partial f(0) \neq \emptyset$, the sequence $\left\{x_{n}\right\}$ converges strongly to a minimizer of $f$ nearest to $u$.

\section{Acknowledgements}

The authors are grateful to the referees for their valuable comments and suggestions which improve the contents of the article.

Author details

${ }^{1}$ School of Mathematics and Information Science, North China University of Water Resources and Electric Power,

Zhengzhou 450011, China ${ }^{2}$ College of Science, Hebei University of Engineering, Handan 056038, China

\section{Authors' contributions}

All authors contributed equally to this paper. All authors read and approved the final manuscript. 


\section{Competing interests}

The authors declare that they have no competing interests.

Received: 9 February 2012 Accepted: 13 June 2012 Published: 13 June 2012

\section{References}

1. Kang, SM, Cho, SY, Liu, Z: Convergence of iterative sequences for generalized equilibrium problems involving inversestrongly monotone mappings. J Inequal Appl. 2010, 827082 (2010)

2. Kim, JK, Cho, SY, Qin, X: Hybrid projection algorithms for generalized equilibrium problems and strictly pseudocontractive mappings. J Inequal Appl 2010, 18 (2010). (Article ID 312602)

3. Lin, LJ, Huang, YJ: Generalized vector quasi-equilibrium problems with applications to common fixed point theorems and optimization problems. Nonlinear Anal TMA. 66, 1275-1289 (2007). doi:10.1016/j.na.2006.01.025

4. Husain, S, Gupta, S: A resolvent operator technique for solving generalized system of nonlinear relaxed cocoercive mixed variational inequalities. Adv Fixed Point Theory. 2, 18-28 (2012)

5. Qin, X, Cho, YJ, Kang, SM: Convergence theorems of common elements for equilibrium problems and fixed point problems in Banach spaces. J Comput Appl Math. 225, 20-30 (2009). doi:10.1016/j.cam.2008.06.011

6. Kim, JK: Strong convergence theorems by hybrid projection methods for equilibrium problems and fixed point problems of the asymptotically quasi-ð-nonexpansive mappings. Fixed Point Theory Appl. 2011 (2011)

7. Cho, SY, Kang, SM: Approximation of common solutions of variational inequalities via strict pseudocontraction. Acta Mathematica Scientia. 32, 1607-1618 (2012)

8. Chang, SS, Lee, HWJ, Chan, CK: A new method for solving equilibrium problem fixed point problem and variational inequality problem with application to optimization. Nonlinear Anal. 70, 3307-3319 (2009). doi:10.1016/..na.2008.04.035

9. Mahato, NK, Nahak, C: Equilibrium problem under various types of convexities in Banach space. J Math Comput Sci. 1, 77-88 (2011)

10. Qin, X, Cho, SY, Kang, SM: Strong convergence of shrinking projection methods for quasi-囚-nonexpansive mappings and equilibrium problems. J Comput Appl Math. 234, 750-760 (2010). doi:10.1016/..cam.2010.01.015

11. Qin, X, Cho, SY, Kang, SM: Convergence of an iterative algorithm for systems of variational inequalities and nonexpansive mappings. J Comput Appl Math. 233, $231-240$ (2009). doi:10.1016/..cam.2009.07.018

12. Mathato, NK, Nahak, C: Equilibrium problem under various types of convexities in Banach space. J Math Comput Sci. 1, 77-88 (2011)

13. Cho, YJ, Kang, SM, Zhou, H: Approximate proximal point algorithms for finding zeroes of maximal monotone operators in Hilbert spaces. J Inequal Appl 2008, 10 (2008). (Article ID 598191)

14. Qin, X, Kang, SM, Cho, YJ: Approximation zeros of monotone operators by proximal point algorithms. J Global Optim. 46, 75-87 (2010). doi:10.1007/s10898-009-9410-6

15. Eckstein, J: Approximate iterations in Bregman-function-based proximal algorithms. Math Program. 83, 113-123 (1998)

16. Güller, O: On the convergence of the proximal point algorithmfor convex minimization. SIAM J Control Optim. 29, 403-419 (1991). doi:10.1137/0329022

17. Tossings, P: The perturbed proximal point algorithm and some of its applications. Appl Math Optim. 29, 125-159 (1994). doi:10.1007/BF01204180

18. Tikhonov, AN: Solution of incorrectly formulated problems and a regularization method. Soviet Math Doklady. 4, $1035-1038$ (1963)

19. Qin, X, Su, Y: Approximation of a zero point of accretive operator in Banach spaces. J Math Anal Appl. 329, 415-424 (2007). doi:10.1016/.j.jmaa.2006.06.067

20. Minty, GJ: On the maximal domain of a monotone function. Michigan Math J. 8, 135-137 (1961)

21. Sahu, DR, Yao, JC: The prox-Tikhonov regularization method for the proximal point algorithm in Banach spaces. J Optim Theory Appl. 151, 641-655 (2011)

22. Verma, RU: Rockafellar's celebrated theorem based on A-maximal monotonicity design. Appl Math Lett. 21, 355-360 (2008). doi:10.1016/j.aml.2007.05.004

23. Agarwa, RP, Verma, RU: Inexact a-proximal point algorithm and applications to nonlinear varia-tional inclusion problems. J Optim Theory Appl. 144, 431-444 (2010). doi:10.1007/s10957-009-9615-3

24. Qin, $X, S u, Y$ : Strong convergence theorems for relatively nonexpansive mappings in a Banach space. Nonlinear Anal. 67, 1958-1965 (2007). doi:10.1016/j.na.2006.08.021

25. Burachik, BS, Scheimberg, S, Svaiter, BF: Robustness of the hybrid extragradient proximal-point algorithm. J Optim Theory Appl. 111, 117-136 (2001). doi:10.1023/A:1017523331361

26. Noor, MA: Splitting algorithms for general pseudomonotone mixed variational inequalities. J Global Optim. 18, 75-89 (2000). doi:10.1023/A:1008322118873

27. Anh, PN, Muu, LD, Nguyen, VH, Srodiot, JJ: Using the Banach contraction principe to implement the proximal point method for multivalued monotone variational inequalities. J Optim Theory Appl. 124, 285-306 (2005). doi:10.1007/ s10957-004-0926-0

28. Cho, SY, Kang, SM: Approximation of fixed points of pseudocontraction semigroups based on a viscosity iterative process. Appl Math Lett. 24, 224-228 (2011). doi:10.1016/..aml.2010.09.008

29. Shehu, Y: A new iterative scheme for a countable family of relatively nonexpansive mappings and an equilibrium problem in Banach spaces. J Global Optim. (2011)

30. Kamimura, S, Kohsaka, F, Takahashi, W: Weak and strong convergence theorems for maximal monotone operators in a Banach space. Set-valed Anal. 12, 417-429 (2004). doi:10.1007/s11228-004-8196-4

31. Moudafi, A: On the regularization of the sum of two maximal monotone operators. Nonlinear Anal. 42, 1203-1208 (2000). doi:10.1016/50362-546X(99)00136-4

32. Qin, X, Cho, YJ, Kang, SM: Viscosity approximation methods for generalized equilibrium problems and fixed point problems with applications. Nonlinear Anal. 72, 99-112 (2010). doi:10.1016/j.na.2009.06.042

33. Martinet, B: Algorithmes pour la Resolution des Problemes d'Optimisation et de Minmax. These d'etat Universite de Grenoble, France (1972) 
34. Rockafellar, RT: Monotone operators and the proximal point algorithm. SIAM J Control Optim. 14, 877-898 (1976). doi:10.1137/0314056

35. Bruck, RE: A strongly convergent iterative method for the solution of $0 \mathbb{Q} U x$ for a maximal monotone operator $U$ in Hilbert space. J Math Appl Anal. 48, 114-126 (1974). doi:10.1016/0022-247X(74)90219-4

36. Liu, L: Ishikawa-type and Mann-type iterative processes with errors for constructing solutions of nonlinear equations involving m-accretive operators in Banach spaces. Nonlinear Anal. 34, 307-317 (1998). doi:10.1016/50362-546X(97) 00579-8

doi:10.1186/1029-242X-2012-137

Cite this article as: Wei and Shi: Convergence of a proximal point algorithm for maximal monotone operators in Hilbert spaces. Journal of Inequalities and Applications 2012 2012:137.

\section{Submit your manuscript to a SpringerOpen ${ }^{\circ}$} journal and benefit from:

- Convenient online submission

- Rigorous peer review

- Immediate publication on acceptance

- Open access: articles freely available online

- High visibility within the field

- Retaining the copyright to your article

Submit your next manuscript at $\boldsymbol{s p r i n g e r o p e n . c o m ~}$ 